\title{
Design of an Energy-saving Home Furnishing Device by Human-body Induction
}

\author{
Linan Zhang \\ Department of Electrical and Electronic Engineering, North China Electric Power University, \\ Beijing, 102206, China
}

Keywords: Human detection, Pyroelectric infrared, Single chip microcomputer, Stepper motor.

\begin{abstract}
China Certification Centre for Energy Conservation Product found in the investigation that the standby energy consumption accounts for about $10 \%$ of the electricity consumption of Chinese family. This paper presents an energy-saving design by human body induction in order to cut off the power supply when no indoor appliances to achieve energy saving. This kind of device can make indoor appliances stop when nobody is in the room. Through the device, it can not only avoid the standby energy consumption of household appliances, but also solve the additional energy issues caused by those who forget to close the electric appliances, thereby reducing the household electricity costs to realize energy saving and emission reduction.
\end{abstract}

\section{The research background and significance}

Under the background of the national energy-saving and emission reduction policies, home Furnishing energy problem has aroused more and more concern. The additional energy consumption of household appliances mainly includes the standby energy consumption and the operating energy consumption caused by the user who forgets to close the home appliances and keeps those appliances under the unnecessary operating state. All of these cause a large waste a lot of energy inadvertently.

\section{The current status of the standby power consumption of household appliances}

A survey of household standby energy consumption and energy-saving potential by China Certification Center for Energy Conservation Product revealed that the standby energy consumption accounts for about $10 \%$ of the electricity consumption of Chinese family. The average standby energy consumption of the city families in our country is equivalent to the situation where these families use an ever-lasting lamp of 15 watts to 30 watts every day. Standby energy consumption is like blood sucking insects sucking electricity and energy everywhere, and meanwhile it also creates enormous pressure on environmental protection. In China, only an item of standby energy consumption of the color TV is equivalent to the total power of several large-scale thermal power plants in the whole country.

Reducing the standby energy consumption not only means that consumers can save electricity costs, but more directly reduces the energy waste and environmental pressure. Therefore, reducing standby energy consumption not only is an electric consumption problem, but more becomes a global-concern and far-reaching issue of sustainable development.

Before the manufacturer has not provided effective energy-efficient appliances, to close the electric power supply is still an effective way to reduce standby energy consumption. Thus, this design of an energy-saving system by human body induction that can cut off the electrical power when no one in interior can achieve energy saving.

\section{Principle}

Apparatus designed for this study mainly includes the following three parts: the detection part, the data transfer part and the control part. The designing idea is: when the master left the room, the infrared signal detected by the probe disappears, and the infrared sensing amplifying detection 
circuit in the room has not received any signal within a certain period of time, then the relay trips and the single-chip microcomputer controls the room appliances branch to open, so the whole device has been automatically entering the energy-saving state.

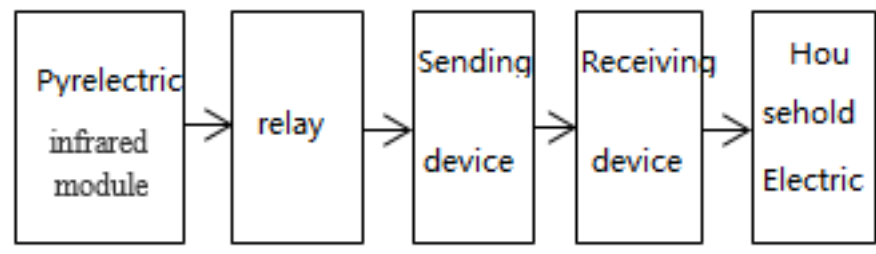

Fig 1:.The simple flow chart

In order to detect that if there is anyone indoor, this design adopts the pyroelectric infrared module. This module has the advantages of high sensitivity and cheap price, and since the launching time is so long, the technology is mature and the reliability is excellent. Later, when the system starts, it first initialized, and then the motor rotates to drive the pyroelectric infrared module to rotate with it to start detecting. The results will be delivered by the local microcontroller through the way of serial port communication to transmit to the receiving microcontroller. The main control chip is responsible for controlling the rotation of the motor and detecting the signal from the receiving microcontroller to further control the start and stop of all household appliances.

\section{The flow chart}

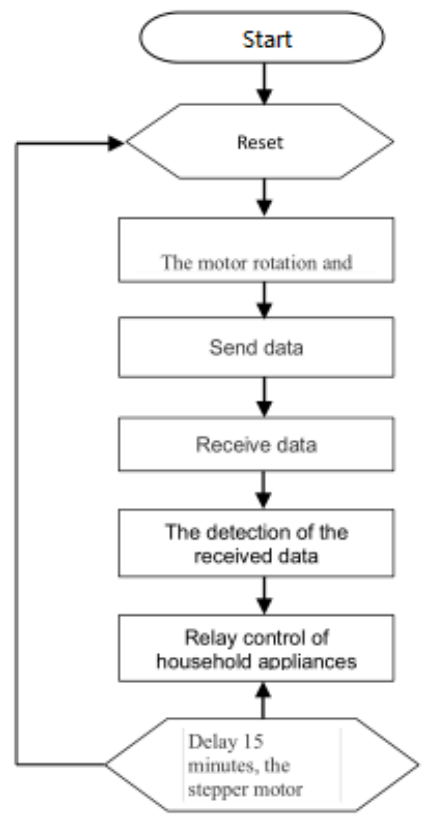

Fig 2: The flow chart

\section{Circuit diagram}

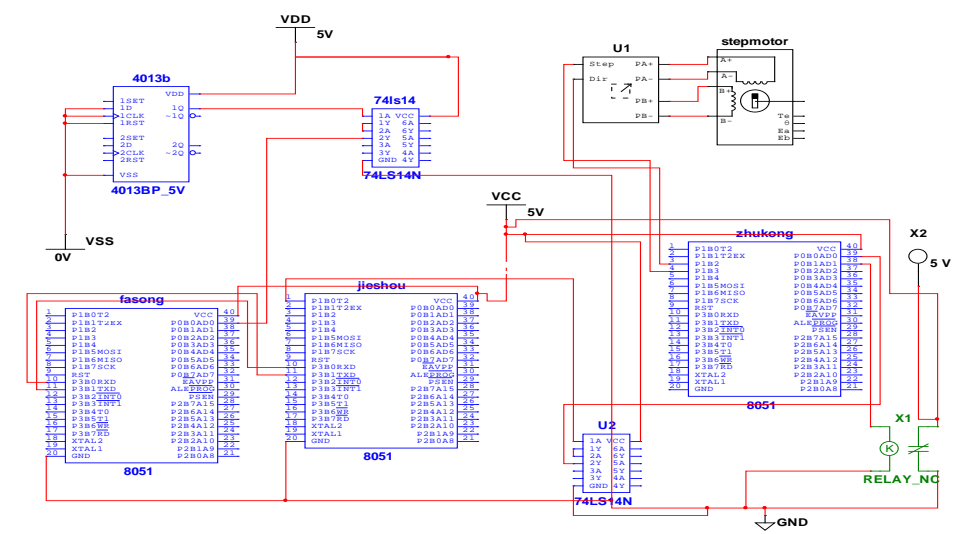

Fig 3: Circuit diagram (The detection part is omitted) 


\section{Design of the experimental device}

Apparatus designed for this study mainly includes the following three parts: the detection part, the data transfer part and the control part. The realization of the device is mainly based on: the sensor system, the relay and the single chip microcomputer.

\section{The detection part}

The detection part is mainly composed of the pyroelectric infrared sensor and the low-speed motor.

\section{Pyroelectric infrared sensor}

Infrared human body detection module is capable of sensing body close to or far away. It can detect the 10 20 m range of human action by equipping in front of the detector with a Fresnel lens. Because it can only detect the dynamic motion of the object, this design is considered to fix it on the rotating shaft of the low speed motor making it moving in a circle, so that the measuring range can be extended to 360 degrees.

Pyroelectric infrared sensor itself does not send any type of radiation. It has low consume, good concealment, low price, automatic induction, wide working voltage range and other function features. And it has good anti-interference performance that can prevent small animals, electromagnetic interference and lighting. It has the blocking time of induction (default: 2.5S blocking time) and each time it detects the activities of the human body, it will be automatically postponed for a period of delay time, and it will use the last activity time as the starting point of the delay time.

In this design, the actual application is taken into account that it needs a preset working time to achieve delay detection function. This delay detection function is designed to be completed by using single-chip microcomputer. The default time is divided into starting-up delay time T1 and closing delay time $\mathrm{T} 2$.

Here we choose an infrared induction module sensor based on the above principle. During the design, taking the actual application into account, we need to preset a working time in order to achieve the function of delay detection. We design to use single chip microcomputer to achieve it. Taking human body infrared induction module product type HC--SR501 as an example, the sensor in this design is installed at the top of the ceiling. And when a person enters the switching sensing range (0-10m effective radius, 140 degree cone angle), it detects the changes of the human body infrared spectroscopy and automatically outputs high level $2.5 \mathrm{~V}$. If the person does not leave the sensing range, it will continue outputting high level, making the single chip microcomputer begin to start delay detection program module. But if the person leaves, the switching-time delay is automatically closed, outputting low level, and therefore the single chip microcomputer is running closing delay program module. Turning-off delay time can be set according to the demand.

This sensor has high sensitivity, strong reliability and low power consumption (its power consumption is lower than $0.00005 \mathrm{~W}$ ), not causing the electric energy loss too large.

In order to achieve all the functions required, we designed a passage of $51 \mathrm{MCU}$ assembler and carried out simulating experiments using single chip comprehensive experimental box.

\section{The Stepper Motor}

Stepper motor is an open loop control element that can convert the electrical pulse signal into angular displacement or line displacement. Its capacity of driving load inertia is large, applicable to those small and medium-sized machine and those places where the requirements of speed and accuracy are not so high.

By adopting the 42BYG250C-SASSML-0151 stepper motor, this design can achieve driving sensing device into rotating operation with a smaller power. In the experimental stage of this design, in view of the insurance account, the power of the motor we selected may be slightly larger, smaller power motor can also drive the device to work theoretically, so the energy saving effect is better after improving it in the following.

\section{The data transfer part:}

In order to simplify the process, reduce the process steps experienced in the data transmission and increase the system's reliability, the design adopts the data transmission method of microcontroller serial port communication with mature technology, simple operation and good stability. Its small 
size, light weight and cheap price provide convenient conditions for the modification, application and development.

This design uses a kind of the most widely used 51 microcontrollers. Being used as the controller, it controls the movements of the equipment connected through the serial port by sending a certain format data. And at the same time, the equipment will return some of their own status information to the microcontroller as feedback for the microcontroller to judge and make the corresponding control.

\section{The control part:}

The relay is an automatic switch element with function of isolation and is one of the most important control elements. As a control element, its main functions are large control range, amplification, combining signal, automation and remote control and monitoring.

Under comprehensive consideration of various factors, the device adopts a common Song Le 12V relay as a test to realize control function. Here in the design, the high level outputs of the infrared sensing amplifier detecting circuit access to one end of the coil of the relay, while the other end is grounded to form a closed circuit. When the master enters the room, after a period of delay time T1, the sensor components output high level, the current is generated in the left loop, relay armature will be attracted to the iron core under the electromagnetic force to overcome the tension of the spring, the movable contact and the static contact pull in and then the right side of the circuit (electromagnetic valve controlling circuit) is switched on. When the master lefts, the sensor components output low level, the electromagnetic force disappears with it, and the armature will return to its original location under the spring reaction force, so that the movable contact and the static contact separate and the right side of the circuit (electromagnetic valve controlling loop) breaks.

\section{Analysis of economic benefits and application prospects}

In order to make the research quantitative, here we take one family as a unit to study the energy saving effect of the device and assume that there are electric lights, a TV, a TV set-top box, 1.5 air conditioners and one desktop computer of five kinds of basic household appliances in each household and they are usually in operation or standby mode when no one in the room.

Table 1: The situation of energy consumption of household appliances

\begin{tabular}{cccccc}
\hline Electrical appliances & $\begin{array}{c}\text { Energy-saving } \\
\text { lamp }\end{array}$ & TV & $\begin{array}{c}1.5 \text { air- } \\
\text { conditioning }\end{array}$ & $\begin{array}{c}\text { TV set-top } \\
\text { box }\end{array}$ & $\begin{array}{c}\text { desktop } \\
\text { computer }\end{array}$ \\
\hline $\begin{array}{c}\text { Power (W) } \\
\text { The standby energy } \\
\text { consumption (W) }\end{array}$ & 30 & 350 & 1125 & 5 & 350 \\
$\begin{array}{c}\text { The normal state when } \\
\text { people leave }\end{array}$ & open & standby & open & standby & standby \\
$\begin{array}{c}\text { The average daily } \\
\text { unnecessary using time (h) }\end{array}$ & 2 & 3 & 0.5 & 3 & 2 \\
\hline
\end{tabular}

According to the table, we can figure out that:

Total unnecessary energy consumption of appliances in every household every day $=0.03 *$ $2+0.002 * 3+1.125 * 0.5+0.0041 * 3+0.001 * 2=0.6428 \mathrm{~kW} \cdot \mathrm{h}$

From that, we can calculate that the unnecessary energy consumption of electrical appliances in one family one year can be up to $231.408 \mathrm{~kW} \cdot \mathrm{h}$. According to the sixth national census data, the total number of Chinese urban households in 2010 is 232,910,000. Supposing that $1 / 25$ of the total nation's families has the situation of unnecessary energy consumption of household appliances, unnecessary energy consumption produced by home appliances nationwide in one year is up to $2,155,890,000 \mathrm{~kW} \cdot \mathrm{h}$. According to reckoning, one $\mathrm{kW} \cdot \mathrm{h}$ of electricity corresponds to 0.4 kilograms of standard coal consumption, while emissions of $0.272 \mathrm{~kg}$ carbon dust, 0.997 kilograms of carbon dioxide, $0.03 \mathrm{~kg}$ of sulfur dioxide and $0.015 \mathrm{~kg}$ of nitrogen oxides. Therefore, because of the unnecessary power consumption of household appliances, there will be about 862,356 tons of extra 
standard coal consumption in our country each year and 586,402 tons of carbon dusts, 2,149,422 tons of carbon dioxide, 64,676 tons of sulfur dioxide and 32,338 tons of nitrogen oxides being increased.

What in the table above is only the general case? But in fact, mutual influence still exists among home appliances because home appliances will be releasing heat in the process of running or being standby. If the TV is in the working state, the power will increase so as the air conditioning. Many people even forget to turn the electrical appliances to the standby state before leaving home, leaving electrical appliances in a state of high energy consumption in operation. This will cause greater energy waste.

The main power consumption of this detecting device lies on the operation of the motor. Considering the dynamic problems into account, when selecting the motor in the beginning, we choose the 42BYG250C-type motor. However, the smaller motor power can actually be enough to drive this device, so we can take the $50 \mathrm{~W}$-average-power motor as an example to calculate. The device completes a testing requiring about 64 seconds, and every 15 minutes once, cutting off the power supply to stop detection. So it need to detect about 90 times one day and the running time is about $1.6 \mathrm{~h}$ with the daily consumption of $0.08 \mathrm{kwh}$. The power consumption is very small.

Table 2: Economic indicators of energy saving estimation

\begin{tabular}{cc}
\hline Project name & index \\
\hline The extra power consumption per household per day before installing the device $(\mathrm{kW} \cdot \mathrm{h})$ & 0.64280 .08 \\
The extra power consumption per household per day after installing the device $(\mathrm{kW} \cdot \mathrm{h})$ & 0.08 \\
The amount of electricity saving every day $(\mathrm{kW} \cdot \mathrm{h})$ & 0.5628 \\
The amount of electricity saving every year $(\mathrm{kW} \cdot \mathrm{h})$ & 202.608 \\
The saving cost of five years $(0.49$ yuan $/ \mathrm{kwh})$ & 496.39 \\
The cost of the device & $\backslash$ \\
The electricity saving income per household & $\backslash$ \\
Total revenue of electricity saving & $\backslash$ \\
\hline
\end{tabular}

\section{Conclusions}

The beneficial effect of this device is that by using this designed human body induction energysaving device, it can accurately and automatically cut off the switch by human body induction with no manual operation needs during the whole process, intelligent and accurate. It can avoid unnecessary power consumption of household appliances basically. Thus, the benefits of energysaving and emission-reduction will be considerable.

We choose a family as a unit in the calculation. In fact, the application scope of the human body detection energy-saving device is extensive, which can be used for the energy-saving of offices, classrooms and many other places. The future of its development appears extremely promising.

\section{References}

[1] Liming He. Single chip advanced tutorial (Application and Design) Beijing: Peking University of Aeronautics and Astronautics Press, 2008. 8.

[2] Zhao’ an Wang. Power electronic technology [M]. Beijing: Mechanical Industry Press, 2000.

[3] Kang Wang, research and Countermeasure of standby power consumption of household appliances, Power. 2007(2). 